\title{
KEBUTUHAN PEMBELAJARAN BAHASA INDONESIA BAGI PENUTUR ASING THAILAND
}

\author{
Elva Riezky Maharany \\ Pendidikan Bahasa dan Sastra Indonesia, Fakultas Keguruan dan Ilmu Pendidikan, \\ Universitas Islam Malang \\ elvmaharany@gmail.com
}

\begin{abstract}
Abstrak
Peningkatan kedudukan Bahasa Indonesia terwujud dengan adanya pembelajaran Bahasa Indonesia bagi Penutur Asing (BIPA). Salah satu pembelajaran yang memiliki karakteristik khusus adalah pembelajaran BIPA Thailand. Berdasarkan kekhususan tersebut maka diperlukan penelitian tentang kebutuhan apa saja yang berkaitan dengan materi pembelajaran. Penelitian ini menggunakan metode penelitian kualitatif dengan jenis penelitian deskriptif. Berdasarkan temuan dapat disimpulkan terdapat 2 pokok temuan yaitu (1) kebutuhan bahasa pengajaran BIPA Thailand dan (2) kebutuhan budaya pengajaran BIPA Thailand. Kebutuhan bahasa pengajaran BIPA terdiri atas kebutuhan materi yang dikelompokkan berdasarkan topik, jenis teks, serta tata bahasa.Terdapat 10 topik, 6 jenis teks, serta 21 materi tata bahasa. Lain halnya dengan kebutuhan budaya pengajaran BIPA yang mengelompokkan aspek kebudayaan menjadi dua yaitu topik dan aspek kebudayaan. Berdasarkan temuan topik yang diperluakan terdiri atas 10 topik sedangkan aspek kebudayaan terdapat 11 aspek yang perlu diajarkan.
\end{abstract}

Kata kunci: Kebutuhan pengajaran, Pengajaran Bahasa Indonesia bagi Penutur Asing, Pemelajar Thailand

\begin{abstract}
Increasing the position of Indonesian Language was realized by the existence of Indonesian Language Learning for Foreign Speakers (BIPA). One of the learning that has special characteristics is BIPA Thai learning. Based on these specificities, research is needed on what needs are related to learning material. This study uses qualitative research methods with descriptive types of research. Based on the findings, it can be concluded that there are 2 main findings, namely (1) the need for BIPA Thai teaching language and (2) the need for BIPA Thai teaching culture. The teaching language needs of BIPA consist of material needs that are grouped by topic, type of text, and grammar. There are 10 topics, 6 types of texts, and 21 grammatical material. It is different from the cultural needs of BIPA's teaching which classifies aspects of culture into two, namely topics and aspects of culture. Based on the findings of the necessary topics
\end{abstract}

Keywords: Teaching needs, Indonesian Language Teaching for Foreign Speakers, Thai Learners

\section{PENDAHULUAN}

Kedudukan Bahasa Indonesia saat ini telah meningkat menjadi bahasa internasional sesuai dengan amanah Undang-Undang Republik Indonesia nomor 24 pasal 44 tahun 2009. Peningkatan kedudukan tersebut diwujudkan dengan munculnya pengajaran Bahasa Indonesia Bagi Penutur Asing (BIPA) yang telah dilaksanakan tidak hanya di dalam negeri melainkan juga di luar negeri. Berdasarkan data yang diperoleh dari darmasiswa.kemdikbud.go.id diketahui bahwa peminat pengajaran BIPA selalu meningkat setiap tahunya. Jumlah alumni pada tahun 2016 sudah mencapai 5719 dari 83 negara.

Berdasarkan data tersebut salah satu negara yang memiliki peminatan tinggi terhadap pengajaran Bahasa Indonesia bagi Penutur Asing adalah negara Thailand. Data lain yang diperoleh dari Pusat Pengembangan Strategi dan Diplomasi Kebahasaan (PPSDK), Badan Pengembangan dan Pembinaan Bahasa, pada tahun 2016 juga menyatakan bahwa terdapat 30 pengajar yang telah dikirim ke Thailand dan tersebar pada 17 lembaga 
dengan jumlah pembelajar mencapai 2.752 orang. Jumlah tersebut merupakan jumlah terbanyak yang pernah dikirim oleh PPSDK pada sebuah negara. Berdasarkan paparan tersebut tampak bahwa pengajaran Bahasa Indonesia bagi Penutur Asing terutama pengajaran di Thailand jika dilihat dari jumlah pembelajarnya mengalami peminatan yang besar.

Negara Thailand memiliki karakteristik khusus yang tampak pada huruf, tata tulis, dan jenis bahasa. Selain itu, negara Thailand memiliki budaya yang berbeda dibandingkan dengan Indonesia. Apabila dilihat dari kedua karakteristik tersebut maka materi ajar yang bisa menyesuaikan dengan karakteristik pemelajar BIPA yang dapat diakses secara umum saat ini yaitu Sahabatku Indonesia Bahan Diplomasi Bahasa Indonesia bagi Penutur Bahasa Thai yang diterbitkan secara daring oleh Kementrian Pendidikan dan Kebudayaan Republik Indonesia. Berdasarkan fakta lapangan tersebut tampak bahwa belum adanya gambaran umum tentang kebutuhan pengajaran BIPA yang berfokus pada pemelajar Thailand.

Penelitian ini merupakan lanjutan dari penelitian tentang karakteristik bahasa tulis pemelajar Thailand dan akan dilanjutkan dengan penelitian pengembangan. Sebelum melakukan penelitian pengembangan maka perlu melakukan penelitian tentang kebutuhan pada pengajaran BIPA Thailand. Hal penting yang perlu dilakukan sebelum pengembangan materi ajar adalah analisis kebutuhan.

Brown (1995: 35) menyatakan bahwa analisis kebutuhan adalah sebuah kegiatan pengumpulan informasi sebagai acuan untuk mengembangkan kurikulum serta kebutuhan pembelajaran siswa. Selain itu, hasil analisis kebutuhan juga dapat digunakan sebagai acuan untuk pengembangan materi ajar. Muliastuti (2016: 146) mengatakan bahwa kebutuhan meliputi enam hal yaitu (1) tujuan umum, (2) tujuan khusus, (3) pengembangan tes, (4) materi ajar, (5) aktivitas pengajaran, serta (6) strategi evaluasi.

Selain itu, Brown (2007: 152) membedakan kebutuhan menjadi dua pokok penting yaitu (1) kebutuhan objektif dan (2) kebutuhan usbjektif. Kebutuhan objektif terdiri atas gambaran awal siswa, kemampuan dan kemahiran bahasa siswa, serta minat siswa. Kebutuuhan subjektif terdiri atas sikap mahasiswa terhadap bahasa target, budaya, tujuan belajar siswa, keterampilan yang diinginkan serta strategi belajar siswa.

Salah satu teori baru yang digunakan untuk menganalisis kebutuhan tersebut adalah analisis SWOT, yakni analisis sebuah keadaan berdasarkan empat hal yaitu (1) strenght (kekuatan) menganalisa keunggulan sumber, (2) weakness (kelemahan) menganalisa keterbatasan serta hambatan sumber, (3) opportunity (peluang) menganilisa situasi yang menguntungkan, serta (4) threat (tantangan) menganalisa situasi yang tidak menguntungkan bagi masa depan (Team FME, 2013: 07). Berdasarkan analisa tersebut maka dapat dikelompokkan menjadi dua kelompok besar yaitu faktor pendukung (kekuatan dan peluang) serta faktor penghambat (kelemahan dan tantangan). Analisa ini merupakan alat yang cocok untuk menjabarkan kebutuhankebutuhan pengajaran BIPA Thailand.

\section{METODE}

Desain penelitian ini adalah kualitatif. Hal tersebut didasarkan pada (1) data penelitian yang berupa hasil wawancara dan hasil studi dokumen,(2) penelitian dilakukan secara alami, serta (3) peneliti sebagai instrumen utama. Pada penelitian ini peneliti menyusun rancangan penelitian, kemudian menyususn rumusan masalah yang terdiri atas kebutuhan bahasa dan kebutuhan budaya pengajaran BIPA Thailand, setelah itu melakukan pengumpulan data berdasarkan rumusan masalah tersebut dengan cara melakukan wawancara dan studi dokumen. Sesudah itu peneliti mengelompokkan data berdasarkan rumusan masalah. Setelah melakukan pengelompokkan data, peneliti melakukan analisis terhadap data temuan kemudian melakukan penyimpulan data. Setelah itu, melakukan validasi data dan diakhiri dengan penyimpulan akhir. Alur penelitian dapat dilihat pada gambar berikut. 


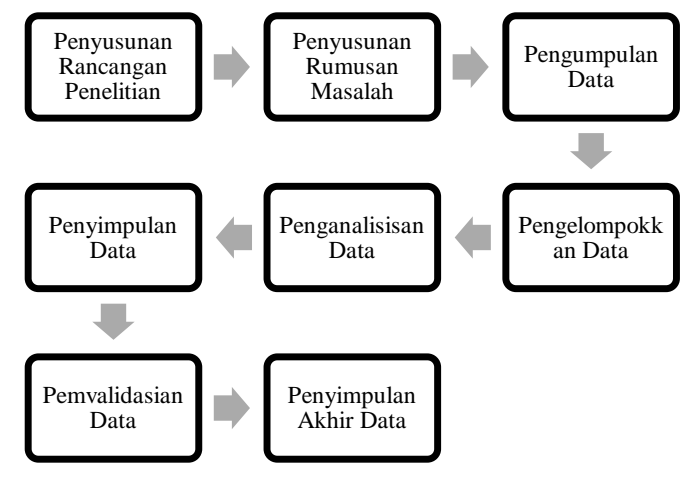

Gambar 1. Desain Penelitian dalam Diagram

Data pada penelitian ini adalah semua informasi lisan dan tertulis tentang kebutuhan bahasa dan budaya pengajaran BIPA Thailand. Data lisan diperoleh dari wawancara kepada pengajar dan pemelajar Thailand. Pengajar pada penelitian ini adalah pengajar dari Indonesia yang mengajarkan BIPA kepada orang Thailand di Thailand, sedangkan pemelajar adalah pemelajar BIPA yang berasal dari Thailand yang belajar Bahasa Indonesia di Thailand kemudian melanjutkan di Indonesia. Data tertulis diperoleh dari studi dokumen pada materi ajar Sahabatku Indonesia Bahan Diplomasi Bahasa Indonesia bagi Penutur Bahasa Thai yang diterbitkan secara daring oleh Kementrian Pendidikan dan Kebudayaan Republik Indonesia. Instrumen yang digunakan adalah pedoman wawancara. Jabaran data tersebut dapat dilihat pada tabel berikut.

Tabel 1. Jabaran Data Penelitian

\begin{tabular}{|l|l|l|l|l|}
\hline No & \multicolumn{1}{|c|}{ Data } & \multicolumn{1}{|c|}{ Sumber Data } & \multicolumn{1}{c|}{$\begin{array}{c}\text { Metode } \\
\text { Pengumpulan Data }\end{array}$} & Instrumen \\
\hline $\mathbf{1}$ & $\begin{array}{l}\text { Bagaimana Kebutuhan Bahasa } \\
\text { pengajaran BIPA Thailand }\end{array}$ & $\begin{array}{l}\text { Pengajar, Pemelajar, } \\
\text { Dokumen }\end{array}$ & $\begin{array}{l}\text { Wawancara dan studi } \\
\text { dokumen }\end{array}$ & $\begin{array}{l}\text { Pedoman } \\
\text { wawancara }\end{array}$ \\
\hline $\mathbf{2}$ & $\begin{array}{l}\text { Bagaimana kebutuhan Budaya } \\
\text { pengajaran BIPA Thailand }\end{array}$ & $\begin{array}{l}\text { Pengajar, Pemelajar, } \\
\text { Dokumen }\end{array}$ & $\begin{array}{l}\text { Wawancara dan Studi } \\
\text { dokumen }\end{array}$ & $\begin{array}{l}\text { Pedoman } \\
\text { wawancara }\end{array}$ \\
\hline
\end{tabular}

Dengan menggunakan analisis SWOT penelitian, peneliti menganalisis kekuatan dari pembelajaran BIPA Thailand, kemudian menganalisis kelemahan dari pembelajaran BIPA Thailand. Setelah itu, menganalisis peluang dan tantangan dari pengajaran BIPA Thailand. Sesudah menganalisis empat hal tersebut yang didapat dari hasil wawancara dan studi dokumentasi maka didapatkan hasil analisis SWOT.

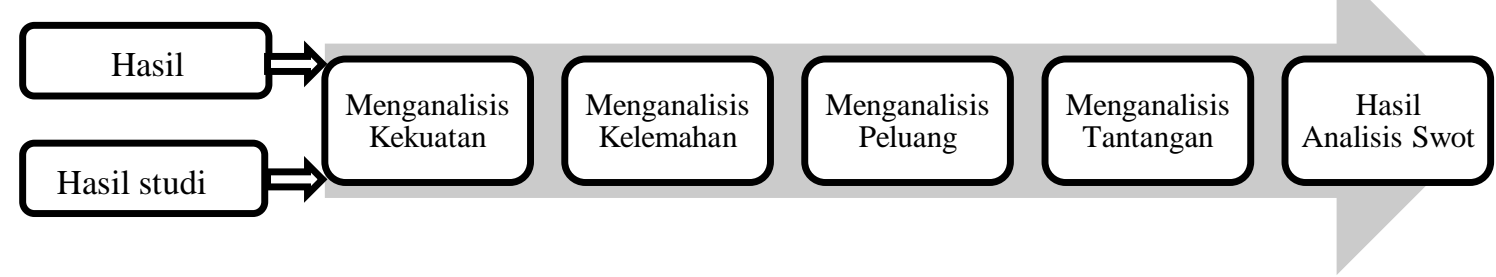

Gambar 2. Diagram Alir Analisis SWOT Pengajaran BIPA Thailand

\section{HASIL DAN PEMBAHASAN}

\section{Kebutuhan Bahasa Pengajaran BIPA Thailand}

Berdasarkan hasil analisis terhadap data yang dikelompokkan menjadi empat kelompok sesuai dengan analisis SWOT yaitu (1) Kekuatan, (2) Kelemahan, (3) Peluang, dan (4) tantangan. Pada kelompok kekuatan ditemukan 3 hal yang menguatkan pengajaran BIPA Thailand yaitu kamus Indonesia-Thailand, KBBI, serta topik yang disukai oleh mahasiswa. Kelompok kekuatan ini dapat diakses dengan mudah melalui telepon genggam ataupun buku cetak.

Kelompok kedua adalah kelemahan, pada kelompok ini terdapat 5 hal kelemahan 
yang muncul saat pengajaran BIPA Thailand yaitu, pemelajar yang pasif, motivasi belajar yang rendah, kurangnya bahan ajar yang cocok dengan bahasa Thailand, pengajaran masih fokus pada guru, serta perbedaan mencolok antara bahasa Thailand dan bahasa Indonesia jika dilihat dari sisi pelafalan, dan cara membaca. Kelompok ketiga adalah peluang, pada kelompok ini terdapat empat hal yang menjadi peluang pengajaran BIPA Thailand yaitu materi bahasa Indonesia mudah dan menarik, materi yang diajarkan berbasis topik, sistematika yang diajarkan dari mudah ke sulit, serta tata bahasa Indonesia sudah mapan. Kelompok terakhir adalah kelompok tantangan, pada kelompok ini terdapat empat hal yaitu tidak adanya kurikulum khusus untuk pengajaran BIPA dengan bahasa Thailand, jumlah siswa yang banyak dalam satu kelas, fasilitas multimedia yang kurang, dan materi ajar kurang menarik.

Berdasarkan keempat kelompok tersebut maka dapat dirumuskan menjadi 6 hal penting yang diperlukan untuk pengajaran BIPA thailand yaitu (1) kurikulum mudah, menarik yang berbasis topik, (2) kurikulum berbasis 4 keterampilan berbahasa, tata bahasa, serta kosakata, (3) materi ajar harus dwibahasa, (4) aktivitas pengajaran harus berfokus pada siswa, (5) materi ajar diawali dengan materi yang mudah ke yang sulit, dan (6) tampilan materi ajar harus menarik.

\begin{tabular}{|c|c|c|c|}
\hline & & Kekuatan & Kelemahan \\
\hline & KEBUTUHAN BAHASA & $\begin{array}{l}\text { Adanya kamus } \\
\text { Indonesia- } \\
\text { Thailand. } \\
\text { Adanya KBBI. } \\
\text { Ada topik yang } \\
\text { disukai oleh } \\
\text { mahasiswa. }\end{array}$ & $\begin{array}{l}\text { Pemelajar pasif. } \\
\text { Motivasi belajar rendah. } \\
\text { Kurangnya bahan ajar. } \\
\text { Pembelajaran fokus pada guru } \\
\text { Perbedaan mencolok antara } \\
\text { bahasa ibu (bahasa Thailand) } \\
\text { dan bahasa target (bahasa } \\
\text { Indonesia). }\end{array}$ \\
\hline ڤ્م & $\begin{array}{l}\text { Materi mudah dan menarik. } \\
\text { Kurikulum berbasis topik. } \\
\text { Sistematika materi yang diajarkan dari } \\
\text { yang mudah ke sulit. } \\
\text { Tata bahasa Indonesia sudah mapan. }\end{array}$ & \multirow{2}{*}{\multicolumn{2}{|c|}{$\begin{array}{l}\text { Kurikulum berbasis topik } \\
\text { Materi ajar terdiri atas } 4 \text { keterampilan berbahasa, tata } \\
\text { bahasa, serta kosakata. } \\
\text { Materi ajar dwibahasa. } \\
\text { Aktivitas pengajaran Student center. } \\
\text { Materi ajar diawali dengan materi yang mudah ke } \\
\text { yang sulit. } \\
\text { Materi ajar dengan tampilan yang menarik. }\end{array}$}} \\
\hline 苞 & $\begin{array}{l}\text { Tidak ada kurikulum } \\
\text { Jumlah siswa yang banyak dalam satu } \\
\text { kelas } \\
\text { Fasilitas multimedia kurang } \\
\text { Materi ajar kurang menarik dari segi } \\
\text { tampilan. }\end{array}$ & & \\
\hline
\end{tabular}

Gambar 3. Jabaran Kebutuhan Bahasa Pengajaran BIPA Thailand berdasarkan analisis SWOT

Berdasarkan hasil studi dokumen terdapat 10 topik yang diajarkan yaitu (1) identitas diri, (2) perkenalan diri, (3) keluarga, (4) tempat tinggal, (5) pekerjaan, (6) makanan, (7) arah dan lokasi, (8) transportasi, (9) kegiatan sehari-hari, dan (10) liburan akhir pekan. Terdapat 4 keterampilan berbahasa yang diajarkan yaitu (1) menyimak, (2) membaca, (3) menulis, dan (4) berbicara. Adapula 6 macam teks yang diajarkan yaitu (1) teks monolog, (2) teks dialog, (3) teks naratif, (4) teks deskriptif, (5) teks prosedural, serta
(6) teks rekon. Selain itu, terdapat 21 tata bahasa yang diajarkan yaitu (1) kata ganti orang 1, (2) ungkapan perkenalan, (3) Struktur kalimat sederhana 1 yang terdiri atas subjek dan predikat, (4) ungkapan selamat, kabar, terima kasih, dan mohon maaf, (5) kata tanya, (6) kata ganti orang 2, (7) kata ganti keluarga, (8) pekerjaan, (9) kata ganti orang 3, kata ganti milik, (10) angka untuk umur, (11) preposisi, (12) Struktur kalimat sederhana S, P, O, K, (13) kata imperatif, (14) kata ganti posisi, (15) kata ganti tunjuk, (16) kata ganti arah, (17) 
kata tunjuk arah, (18) petunjuk lokasi, (19)

lalu, setelah itu, sesudah itu)

(20)

konjungsi sederhana (dan, atau, kemudian,

modalitas, serta (21) kuantitas.

Tabel 2. Jabaran Kebutuhan Materi Kebahasaan

\begin{tabular}{|c|c|c|c|}
\hline Topik & $\begin{array}{c}\text { Keterampilan } \\
\text { berbahasa }\end{array}$ & Jenis teks & Tata bahasa \\
\hline \multirow[t]{4}{*}{ Identitas diri } & Menyimak & \multirow[t]{4}{*}{ Teks monolog } & \multirow{4}{*}{$\begin{array}{l}\text { Kalimat sederhana (subjek + predikat) } \\
\text { Kata ganti orang } 1 \\
\text { (saya, aku, ku, kita, kami) }\end{array}$} \\
\hline & Membaca & & \\
\hline & Menulis & & \\
\hline & Berbicara & & \\
\hline \multirow[t]{6}{*}{ Perkenalan diri } & Menyimak & \multirow[t]{6}{*}{ Teks dialog } & \multirow{6}{*}{$\begin{array}{l}\text { Ucapan selamat } \\
\text { Ungkapan kabar } \\
\text { Ungkapan terima kasih } \\
\text { Ungkapan mohon maaf } \\
\text { Kata tanya } \\
\text { Kata ganti orang } 2 \\
\text { Kamu, anda, mu, kalian }\end{array}$} \\
\hline & Membaca & & \\
\hline & Menulis & & \\
\hline & Berbicara & & \\
\hline & & & \\
\hline & & & \\
\hline \multirow[t]{4}{*}{ Keluarga } & Menyimak & Teks dialog & \multirow{4}{*}{$\begin{array}{l}\text { Kata ganti keluarga } \\
\text { Pekerjaan } \\
\text { Kata ganti orang 3: } \\
\text { Dia, beliau, nya, mereka } \\
\text { Angka untuk umur }\end{array}$} \\
\hline & Membaca & Teks deskripsi & \\
\hline & Menulis & & \\
\hline & Berbicara & & \\
\hline \multirow[t]{4}{*}{ Tempat tinggal } & Menyimak & Teks dialog & \multirow{4}{*}{$\begin{array}{l}\text { Preposisi } \\
\text { Struktur kalimat sederhana } \\
\text { Subjek+predikat+objek+keterangan }\end{array}$} \\
\hline & Membaca & Teks deskripsi & \\
\hline & Menulis & & \\
\hline & Berbicara & & \\
\hline \multirow[t]{4}{*}{ Pekerjaan } & Menyimak & Teks dialog & \\
\hline & Membaca & \multirow[t]{3}{*}{ Teks narasi } & \\
\hline & Menulis & & \\
\hline & Berbicara & & \\
\hline \multirow[t]{4}{*}{ Makanan } & Menyimak & Teks dialog & \multirow[t]{4}{*}{ Kata imperatif } \\
\hline & Membaca & Teks prosedural & \\
\hline & Menulis & & \\
\hline & Berbicara & & \\
\hline \multirow[t]{4}{*}{ Arah dan lokasi } & Menyimak & \multirow{4}{*}{$\begin{array}{l}\text { Teks dialog } \\
\text { Teks deskriptif }\end{array}$} & \multirow{4}{*}{$\begin{array}{l}\text { Kata ganti tunjuk } \\
\text { Kata ganti posisi } \\
\text { Kata ganti jarak } \\
\text { Kata tunjuk arah } \\
\text { Petunjuk lokasi }\end{array}$} \\
\hline & Membaca & & \\
\hline & Menulis & & \\
\hline & Berbicara & & \\
\hline \multirow[t]{4}{*}{ Transportasi } & Menyimak & \multirow{4}{*}{$\begin{array}{l}\text { Teks dialog } \\
\text { Teks deskriptif }\end{array}$} & \\
\hline & Membaca & & \\
\hline & Menulis & & \\
\hline & Berbicara & & \\
\hline \multirow{4}{*}{$\begin{array}{l}\text { Kegiatan sehari- } \\
\text { hari }\end{array}$} & Menyimak & \multirow{4}{*}{$\begin{array}{l}\text { Teks dialog } \\
\text { Teks narasi }\end{array}$} & \multirow{4}{*}{$\begin{array}{l}\text { Konjungsi } \\
\text { Dan, atau, kemudian, lalu, setelah itu, } \\
\text { sesudah itu }\end{array}$} \\
\hline & Membaca & & \\
\hline & Menulis & & \\
\hline & Berbicara & & \\
\hline \multirow{4}{*}{$\begin{array}{l}\text { Liburan akhir } \\
\text { pekan }\end{array}$} & Menyimak & \multirow{4}{*}{$\begin{array}{l}\text { Teks dialog } \\
\text { Teks monolog } \\
\text { Teks rekon }\end{array}$} & \multirow{4}{*}{$\begin{array}{l}\text { Modalitas } \\
\text { Kuantitas }\end{array}$} \\
\hline & Membaca & & \\
\hline & Menulis & & \\
\hline & Berbicara & & \\
\hline
\end{tabular}




\section{Kebutuhan Budaya Pengajaran BIPA Thailand}

Berdasarkan hasil analisis SWOT yang didapatkan dari wawancara kepada narasumber yaitu pembelajar BIPA Thailand dan pengajar BIPA Thailand didapatkan empat hal yaitu (1) kekuatan, (2) kelemahan, (3) peluang, dan (4) tantangan. Kekuatan budaya pada pengajaran BIPA Thailand terletak pada kesamaan budaya ASIA. Kelemahan budaya yang terdapat di pengajaran BIPA Thailand terletak pada budaya pengajaran yang teacher center. Peluang budaya yang ada yaitu sopan santun kepada guru yang tinggi. Sedangkan tantangan yang dihadapi adalah budaya gender yang berbeda dengan di Indonesia. Berdasarkan temuan tersebut dapat dibuatkan solusi untuk kebutuhan budaya yaitu (1) memberikan catatan budaya yang dapat dicantumkan pada materi pembelajaran, (2) dapat mengganti teacher center menjadi student center dengan menyatukan budaya yang mirip (bentuk sapaan, ungkapan kehormatan dalam bahasa Indonesia) pada topik pembelajaran, (3) sopan santun kepada guru yang bisa dilakukan saat pengajaran (budaya di Thailand dan budaya di Indonesia), dan (4) pengetahuan gender yang perlu diketahui oleh pengajar BIPA Thailand yaitu gender gay, lesbi, transgender, serta ladyboy. Temuan tersebut dapat diamati pada gambar berikut.

\begin{tabular}{|c|c|c|c|}
\hline \multirow{2}{*}{\multicolumn{2}{|c|}{ Kebutuhan Budaya }} & Kekuatan & Kelemahan \\
\hline & & Sama budaya ASIA & Budaya pengajaran yang teacher center \\
\hline Peluang & $\begin{array}{l}\text { Sopan } \\
\text { kepada guru yang } \\
\text { tinggi. }\end{array}$ & \multirow{2}{*}{\multicolumn{2}{|c|}{$\begin{array}{l}\text { Memberikan catatan budaya di materi pembelajaran } \\
\text { Mengganti teacher center menjadi student center dengan } \\
\text { menyatukan budaya yang mirip pada topik pembelajaran. } \\
\text { Sopan santun kepada guru (siswa biasa menyapa dengan salam, } \\
\text { tangan di dada) } \\
\text { Pengetahuan gender pada pengajar BIPA Thailand (bahwa di } \\
\text { Thailand gender tidak pernah membedakan laki-laki dan } \\
\text { perempuan, tetapi ada banyak jenis gender seperti gay, lesbi, } \\
\text { transgender, ladyboy, dll). }\end{array}$}} \\
\hline Tantangan & $\begin{array}{l}\text { Budaya gender } \\
\text { yang berbeda } \\
\text { dengan di Indonesia }\end{array}$ & & \\
\hline
\end{tabular}

Gambar 4. Jabaran Kebutuhan Budaya Berdasarkan Analisis SWOT

Berdasarkan studi dokumen terhadap topik yang telah dianalisis pada buku Sahabatku Indonesia Bahan Diplomasi Bahasa Indonesia bagi Penutur Bahasa Thai, terdapat 11 aspek budaya yang dibutuhkan yaitu (1) ungkapan sapaan, (2) senyum dan bersalaman, (3) keluarga dan marga, (4) kerja sambilan, waktu bekerja, dan waktu sekolah di Indonesia, (5) hubungan dengan tetangga, (6) gotong royong, (7) makanan pokok di Indonesia, (8) kebiasaan penunjuk landmark sebagai penunjuk arah, (9) sepeda motor dan gojek, (10) kebiasaan aktivitas Indonesia yang dimulai pagi hari, (11) kebiasaan menghabiskan waktu dengan keluarga, berwisata, dan bermusyawarah.
Tabel 3. Jabaran Kebutuhan Budaya Berdasarkan Topik

\begin{tabular}{|l|l|}
\hline \multicolumn{1}{|c|}{ Topik } & \multicolumn{1}{c|}{ Aspek budaya } \\
\hline $\begin{array}{l}\text { Identitas } \\
\text { diri }\end{array}$ & Ungkapan sapaan \\
\hline Perkenalan & Senyum dan bersalaman \\
\hline Keluarga & Keluarga dan marga \\
\hline $\begin{array}{l}\text { Tempat } \\
\text { tinggal }\end{array}$ & $\begin{array}{l}\text { Kerja sambilan, waktu bekerja, } \\
\text { dan waktu sekolah }\end{array}$ \\
\hline Pekerjaan & $\begin{array}{l}\text { Hubungan dengan tetangga } \\
\text { Gotong royong }\end{array}$ \\
\hline Makanan & Makanan pokok di indonesia \\
\hline $\begin{array}{l}\text { Arah dan } \\
\text { lokasi }\end{array}$ & $\begin{array}{l}\text { Kebiasaan penunjuk landmark } \\
\text { dibandingkan arah }\end{array}$ \\
\hline Transportasi & Sepeda motor dan gojek \\
\hline $\begin{array}{l}\text { Kegiatan } \\
\text { sehari-hari }\end{array}$ & $\begin{array}{l}\text { Aktivitas Indonesia yang } \\
\text { dimulai sangat pagi }\end{array}$ \\
\hline $\begin{array}{l}\text { Liburan } \\
\text { akhir pekan }\end{array}$ & $\begin{array}{l}\text { Menghabiskan waktu dengan } \\
\text { keluarga, berwisata, dan } \\
\text { bermusyawarah }\end{array}$ \\
\hline
\end{tabular}




\section{SIMPULAN}

Berdasarkan hasil dan pembahasan dapat disimpulkan bahwa terdapat 2 pokok temuan yaitu (1) kebutuhan bahasa pengajaran BIPA Thailand dan (2) kebutuhan budaya pengajaran BIPA Thailand. Kebutuhan bahasa pengajaran BIPA terdiri atas kebutuhan materi yang dikelompokkan berdasarkan topik, jenis teks, serta tata bahasa.Terdapat 10 topik, 6 jenis teks, serta 21 materi tata bahasa. Lain halnya dengan kebutuhan budaya pengajaran BIPA, kebutuhan budaya ini

\section{DAFTAR PUSTAKA}

Brown, H. 2007. Principles of Language Learning and Teaching Fifth Edition. New York: Pearson Education.

Muliastuti, L. 2017. Bahasa Indonesia bagi Penutur Asing: Acuan Teori dan terbagi menjadi dua hal yaitu topik dan aspek kebudayaan. Berdasarkan temuan topik yang diperluakan terdiri atas 10 topik sedangkan aspek kebudayaan terdiri atas 11 aspek yang perlu diajarkan.

Berdasarkan temuan tersebut, bagi pengajar BIPA disarankan agar temuan ini dapat menjadi data awal untuk pengembangan silabus, materi ajar, maupun evaluasi dalam pengajaran BIPA Thailand. Bagi peneliti lain diharapkan agar temuan ini menjadi dasar untuk penelitian selanjutnya.

Pendekatan Pengajaran. Jakarta: Yayasan Obor Indonesia.

Suyitno, I. 2005. Bahasa Indonesia untuk Penutur Asing: Teori, Strategi, dan Aplikasi Pengajarannya. Yogyakarta: GrafikIndah. 